Casos Clínicos

Arch. Esp. Urol., 61, 8 (924-929), 2008

\title{
CELULITIS DE PENE TRAS SEXO ORAL
}

Francisco Serrano de la Cruz Torrijos, Francisco Javier Ramada Benlloch, Joaquín Ulises Juan Escudero, Milagros Fabuel Deltoro, Emilio López Alcina, Pedro Navalón Verdejo, Macarena Ramos de Campos y Emilio Marqués Vidal.

Servicio de Urología. Consorcio Hospital General Universitario. Valencia. España.

Resumen.- OBJETIVO: En la actualidad la prevalencia de relaciones sexuales en las que se incluye sexo oral es elevada, esto conlleva una serie de peculiaridades en las infecciones, balanopostitis y celulitis, que pueden producirse en relación con estas prácticas.

MÉTODOS: Aportamos 2 nuevos casos de celulitis peneana tratados en el Servicio de Urología de nuestro hospital.

Francisco Serrano de la Cruz Torrijos

\& Lanas, 38.

ঠे La Solana

(ิ) 13240 Ciudad Real. (España).

¿ pacoserrano_cruz@comv.es

O

Trabajo recibido: 21 de diciembre 2007. 
DISCUSIÓN: Revisamos las indicaciones de profilaxis, tratamiento médico y quirúrgico referidas en la literatura y practicadas en nuestros pacientes.

CONCLUSIONES: La anamnesis ante balanopostitis y celulitis peneanas, debe incluir referencias explícitas a la práctica de sexo oral. La precocidad en el tratamiento, tanto médico como quirúrgico, influye favorablemente en la evolución de las lesiones.

Palabras clave: Pene. Sexo oral. Celulitis.

Summary.- OBJECTIVE: Nowadays, there is the high prevalence of sexual intercourse including oral sex, which implies some peculiarities in the infections, balanitis and ceUlulitis they may produce.

METHODS: We report two new cases of penile cellulitis treated in the urology department in our hospital.

DISCUSSION: We review the indications of prophylaxis, and the medical and surgical treatment both referred in the literature and carried out in our patients.

CONCLUSIONS: When dealing with balanitis and penile cellulitis, the history should include explicit references to the practice of oral sex. Early medical or surgical treatment has a favourable influence on the evolution of the lesions.

Keywords: Penis. Oral sex. Cellulitis. graves se consulta al urólogo. Se trata de una patología que puede ser desde banal a muy grave, llegando a veces a precisar tratamiento quirúrgico urgente para evitar el desarrollo de una necrosis y afectación sistémica.

\section{MATERIAL Y MÉTODO}

El objetivo de este artículo es revisar la literatura existente sobre celulitis peneana aportando dos nuevos casos que hemos tratado en nuestro servicio en un periodo comprendido entre mayo y noviembre de 2007.

\section{RESULTADOS}

\section{CASO CLÍNICO 1}

Paciente de 41 años de edad que acude a urgencias por presentar fiebre de $39^{\circ}$, dolor y edematización progresiva de la piel del pene de una semana de evolución.

Refiere tener pareja estable y no haber mantenido relación de riesgo. Lleva tratamiento antibiótico con amoxicilina-clavulánico desde hace 5 días, prescrito por su médico de atención primaria, sin notar mejoría.

En la exploración física destaca la presencia de un importante edema con áreas vesiculo-ampollosas purulentas no fluctuantes en prepucio (Figura 1).

Indagando sobre la posible etiología del proceso, se realiza una anamnesis más exhaustiva, en la cual el paciente no refiere picadura de insectos ni inoculación de material exógeno en el pene, siendo el único antecedente destacable el haber mantenido sexo oral con su pareja habitual, que no había comentado previamente por considerar nula la relevancia de este hecho.

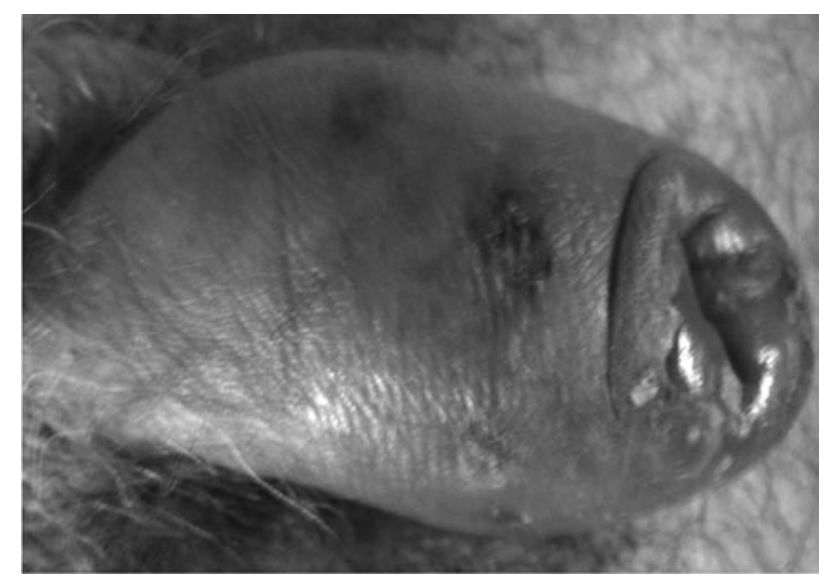

FIGURA 1. Edema peneano con áreas vesículo-ampollosas.$$
\text { vesiculo-ami }
$$

Las balanopostitis, que sólo afectan superficialmente la piel de prepucio y glande, así como las celulitis, que penetran en mayor profundidad hasta el tejido celular subcutáneo, referidas tras relaciones sexuales en las que se incluye sexo oral, son una patología que suele ser atendida, en primera instancia, por médicos de atención primaria y dermatólogos, siendo en muchas ocasiones omitida la causa de la lesión y autotratadas por el paciente, sobre todo en casos leves (1), dada la vergüenza que le supone comentar las circunstancias en que se produjo la lesión.

Considerando que el $90 \%$ de las parejas jóvenes heterosexuales incluye entre sus relaciones el sexo oral, y éste forma parte de todas las relaciones homosexuales, cabe suponer que la prevalencia de este tipo de lesiones debe ser alta $(2,3)$, aunque sólo en los casos más 
La analítica sanguínea muestra leucocitosis (24200 / ul) con desviación izquierda (neutrófilos 90.1\%), PCR $17.36 \mathrm{mg} / \mathrm{dl}$, resto de parámetros dentro de la normalidad. También se realiza cultivo de una flictena.

Con el diagnóstico de celulitis peneana ingresa para completar estudio y tratamiento.

Durante su estancia hospitalaria se le administra gentamicina $240 \mathrm{mg}$ iv / 24 horas (3 días) más clindamicina $600 \mathrm{mg}$ iv / 8 horas (3 días). Como medidas de soporte se añaden analgésicos y antiinflamatorios y se realizan curas locales diarias con agua oxigenada y povidona yodada. El paciente había sido vacunado del tétanos hacía 6 años, por lo que se le administró una dosis de toxoide.

La evolución es favorable con el tratamiento antibiótico, presentando además drenaje espontáneo de las lesiones del pene, obteniendo tejido para cultivo (Figura 2).

Los resultados del estudio microbiológico fueron: flora mixta, anaerobios y espiroquetas; y para el cultivo del tejido (posterior al tratamiento antibiótico): Proteus vulgaris y $E$. coli sensibles a amoxicilina-clavulánico, gentamicina y cotrimoxazol.

Tras 3 días de ingreso hospitalario es dado de alta con el siguiente tratamiento: cotrimoxazol $800 / 160 \mathrm{mg} / 12$ horas vía oral durante 10 días y cura local diaria con suero fisiológico y povidona yodada.

Posteriormente se le practica postectomía diferida (10 días) sin complicaciones, obteniendo los resultados que se observan en la figura 3, a la semana de la intervención.

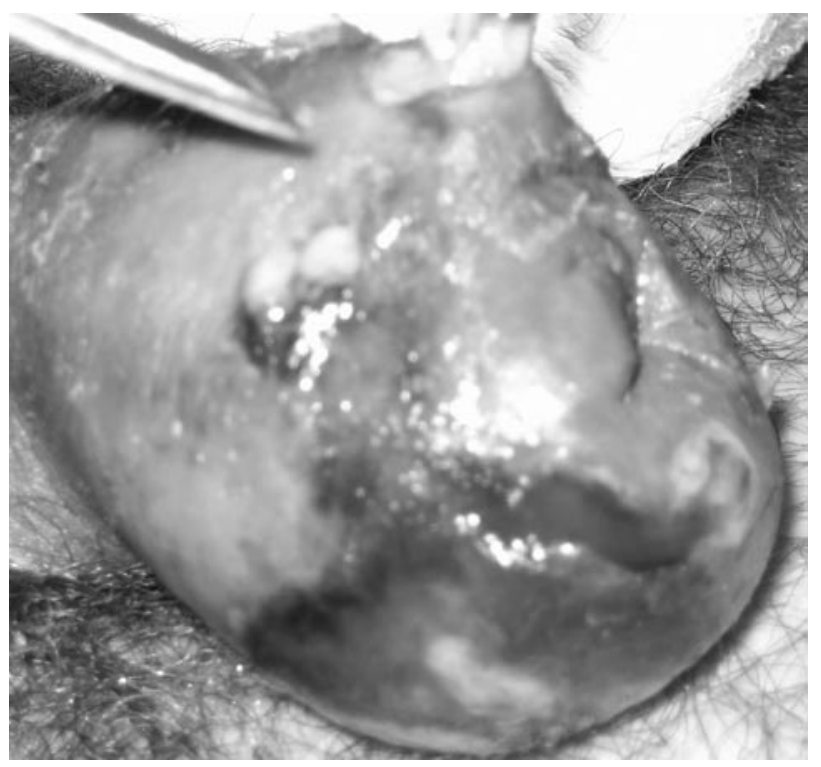

\section{CASO CLÍNICO 2}

Paciente de 25 años de edad que acude a urgencias de nuestro centro por presentar zona indurada muy dolorosa con signos inflamatorios en pene de 3 días de evolución que ha ido empeorando progresivamente, a pesar de iniciar tratamiento con amoxicilina-clavulánico el día previo. No tiene fiebre ni síntomas miccionales acompañantes. Refiere tener pareja estable y no haber mantenido relación de riesgo.

Como antecedentes personales refiere un episodio similar 3 meses antes, aunque menos intenso, que cedió con tratamiento médico (amoxicilina-clavulánico). No presenta alergias medicamentosas conocidas ni otros antecedentes médico-quirúrgicos de interés.

A la exploración física se observa en el pene importante celulitis con áreas de fluctuación (Figuras 4 y 5 ).

Al igual que en el caso anterior al realizar una anamnesis más exhaustiva, el paciente no refiere picadura de insectos ni inoculación de material exógeno en el pene, siendo el único antecedente destacable el haber mantenido sexo oral con su pareja habitual, que no había comentado previamente por considerarlo irrelevante.

La analítica sanguínea revela leucocitosis (13200/ul) con desviación izquierda (neutrofilia 77.7\%), PCR 3 $\mathrm{mg} / \mathrm{dl}$, estando el resto de parámetros dentro de la normalidad.

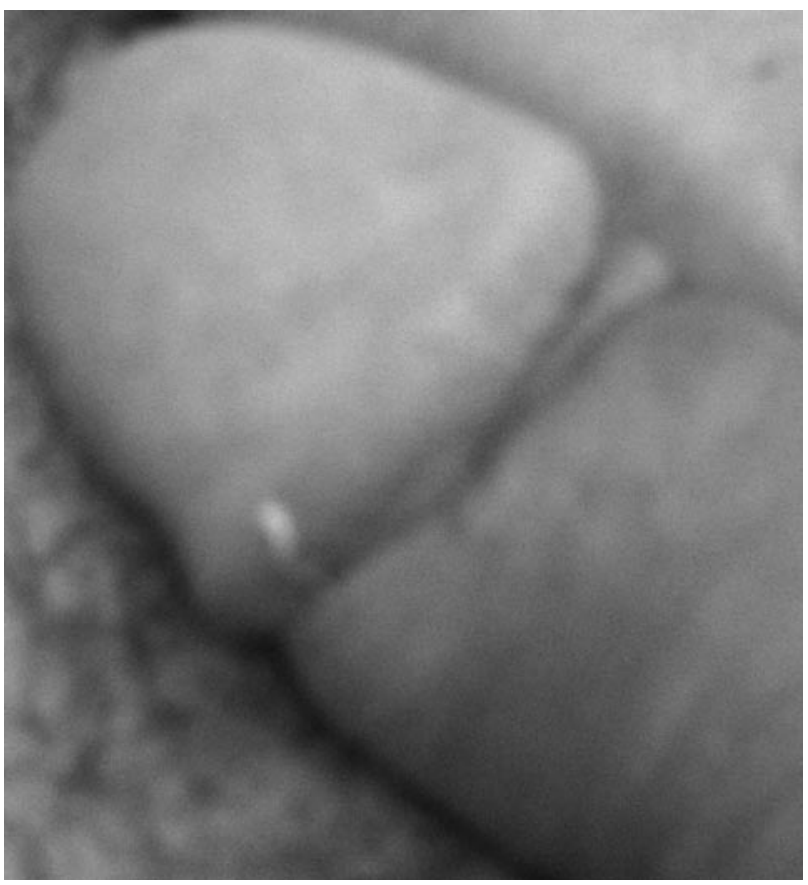

FIGURA 3. Resultado tras postectomía. 


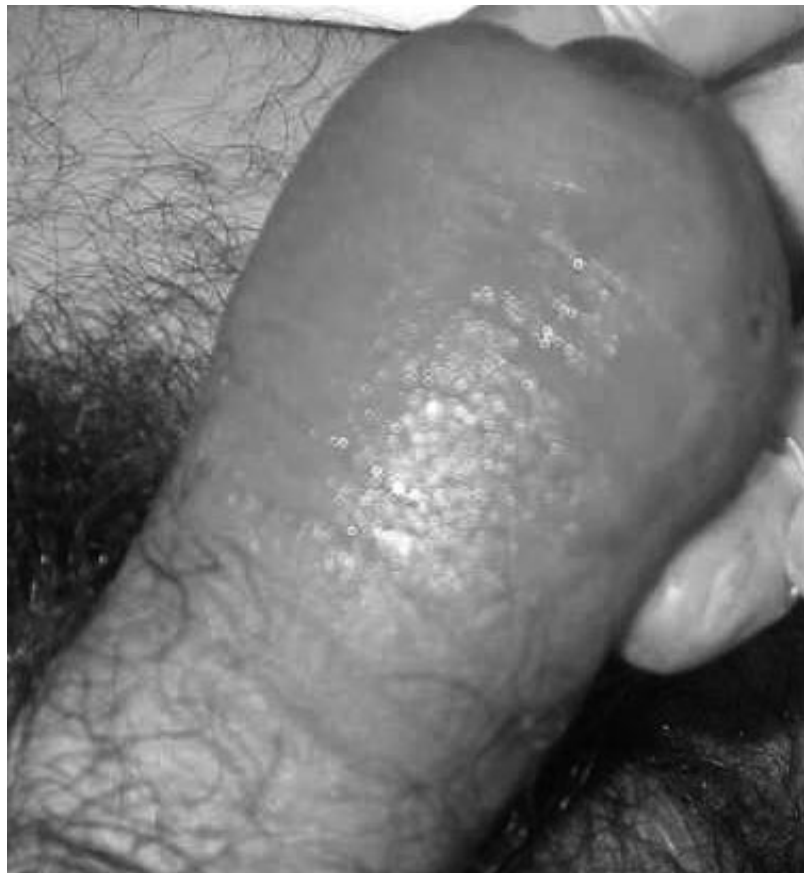

FIGURA 4. Celulitis con áreas de fluctuación.

Se realiza desbridamiento en quirófano de urgencias, obteniendo material para cultivo (Figura 6) y se ingresa al paciente con el diagnóstico de celulitis peneana, para continuar con tratamiento antibiótico parenteral, con amoxicilina-clavulánico $1 \mathrm{~g}$ iv / 8 horas, así como analgésicos y antiinflamatorios y curas locales diarias con agua oxigenada y povidona yodada. El paciente no recordaba la fecha de su última vacunación del tétanos por lo que se le aplicó una pauta completa de vacunación ( 3 dosis de toxoide) y la gammaglobulina antitetánica.

Evoluciona favorablemente, siendo dado de alta al tercer día de ingreso con el siguiente tratamiento: amoxicilina-clavulánico $875 / 125 \mathrm{mg} 1$ comp cada 8 horas (10 días), cura diaria con suero fisiológico y povidona yodada. El cultivo del material obtenido durante la cirugía resulta negativo, por lo que decidimos continuar con el mismo tratamiento al haber respondido adecuadamente.

Posteriormente se revisó al paciente en consultas externas de urología para valorar la necesidad de una postectomía diferida, que no fue necesaria.

\section{DISCUSIÓN}

Las heridas por sexo oral son particularmente problemáticas, por la fragilidad de los tejidos a nivel de los genitales y por el gran riesgo de infección, potencialmente destructiva producida por la flora oral, que en función de la profundidad de la lesión, puede variar

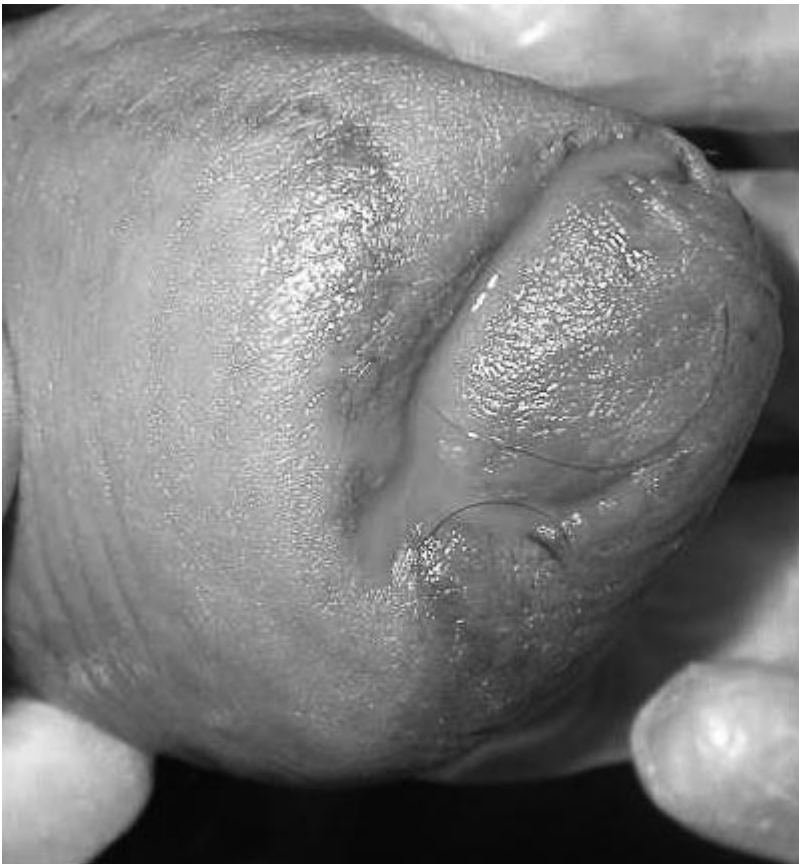

FIGURA 5. Drenaje de contenido purulento.

desde erosiones, provocadas por aparatos de ortodoncia hasta auténticas mordeduras, pudiendo tener como morbilidad asociada la transmisión de sífilis, hepatitis $B$ y $C$, tétanos, tuberculosis, herpes simple, actinomicosis e incluso $\mathrm{VlH}$. El riesgo de transmisión de alguna de estas enfermedades es mayor si la lesión es producida por personas de alto riesgo, como prostitutas, adictos a drogas por vía parenteral y homosexuales promiscuos $(1$, $4,5)$. Estas circunstancias fueron tomadas en consideración a la hora de establecer diagnóstico y tratamiento, aunque no concurrían en nuestros pacientes.

La infección asociada a estas lesiones originada por los microorganismos que habitan en la cavidad bucal y que

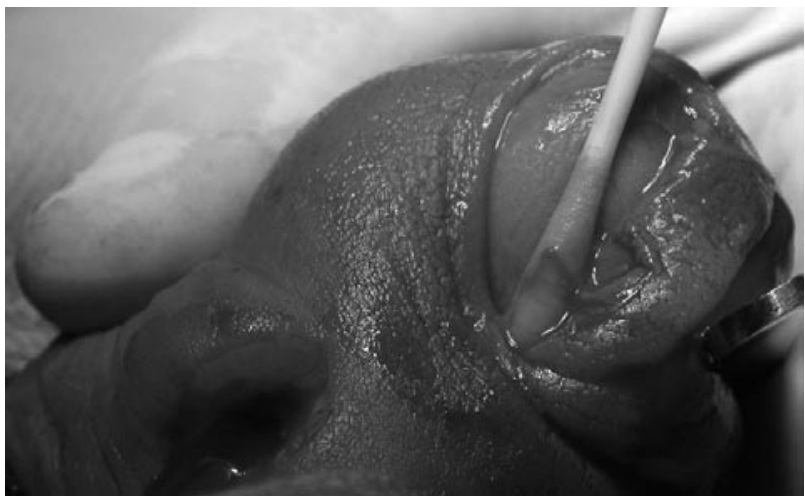

FIGURA 6. Desbridamiento quirúrgico y obtención de muestra para cultivo. 
se transmiten con la saliva, supone una complicación importante que se manifiesta como balanopostitis, laceración exudativa, úlcera, o celulitis $(1,6,7)$, pudiendo llegar incluso a desarrollar una gangrena y sepsis, si la lesión es de tamaño considerable o el paciente está inmunodeprimido.

En una boca normal existen más de 42 especies bacterianas distintas, aumentando en caso de gingivitis o periodontitis $(4,7)$. La saliva humana contiene tanto anaerobios (Bacteroides fragilis, Prevotella, Porphyromonas, Peptostreptococos, Fusobacterium, Veillonella y Clostridium) como aerobios (estreptococos alfa y beta hemolíticos (2x107 microorganismos/ml), Staphylococcus aureus y epidermidis (5x103 microorganismos/ml), Corynebacterium y Eikenella corrodens. Históricamente el S. aureus se ha asociado con infecciones más severas y frecuentemente produce beta lactamasas, siendo resistente a penicilina.

Las balanopostitis y celulitis por espiroquetas o anaerobios son más frecuente en no circuncidados. La mala higiene crea un ambiente debajo del prepucio que favorece el crecimiento bacteriano (8). El diagnóstico de presunción de la balanitis asociada a espiroquetas puede hacerse en presencia de una úlcera extensa y blanda acompañada de supuración maloliente, como en el caso número 1.

Durante la asistencia primaria es primordial obtener una anamnesis detallada con respecto a la naturaleza y momento en que se produjo la lesión y antecedentes patológicos; exploración física, con atención a los genitales; y estudios de laboratorio. En cuanto a los antecedentes del paciente es importante preguntar por factores de riesgo como diabetes, esplenectomía, enfermedades hepáticas, inmunodepresión, alergias medicamentosas y estado de inmunización del tétanos $(1,5,7)$.

El manejo de la infección de la herida por mordedura humana o simplemente sexo oral, como los casos que nos ocupan, se basa fundamentalmente en el conocimiento de la bacteriología y experiencia clínica (7). El tratamiento precoz, tanto médico como quirúrgico, puede minimizar o incluso prevenir las complicaciones $(1,6)$, como se observa en nuestros pacientes, el caso número 1 que acudió tras una semana de evolución tenía mayor componente necrótico y precisó una cirugía diferida, mientras que el caso número 2 que consultó antes de 72 horas sólo requirió un mínimo desbridamiento quirúrgico.

La literatura médica sobre mordeduras justifica la decisión de iniciar tratamiento con antibióticos en caso de infección. La profilaxis debe instaurarse en pacientes con riesgo elevado (7). Las heridas en el pene las debemos considerar como de alto riesgo debido a que la pérdida de tejido celular subcutáneo permite la fácil penetración bacteriana, estando además próximo el reservorio anorrectal de gérmenes.
La elección del antibiótico es controvertida, ya que los datos científicos disponibles se han obtenido sobre estudios in vitro, los cuales son un pobre reflejo de la realidad clínica (10). La efectividad in vivo depende de una suma de factores de absorción, niveles titulares, estado inmune y la relación entre las especies bacterianas.

El tratamiento empírico debe cubrir S. aureus, E. corrodens, Haemophilus y anaerobios. (6) La combinación de una penicilina de amplio espectro con un inhibidor de la betalactamasa (amoxicilina-ácido clavulánico, ticararcilina-ácido clavulánico, ampicilina-sulbactam) parece ofrecer una cobertura adecuada. Amoxicilina clavulánico fue la primera elección en ambos pacientes aunque sin respuesta en el caso número 1 . En pacientes alérgicos a penicilina la elección es más difícil, se basa fundamentalmente en la sensibilidad in vitro y parece razonable la combinación de un antibiótico activo frente a cocos gram positivos y anaerobios, como clindamicina, más fluorquinolonas (adultos) o trimetoprim-sulfometoxazol (niños). En cuanto a la duración, será de 10-14 días en caso de infección y de 5-7 días para la profilaxis $(6,7$, 9). Las cefalosporinas de segunda y tercera generación son muy efectivas y se deberían reservar para situaciones especiales. En nuestro caso clínico número 1, como el paciente no había mejorado con administración de amoxicilina-clavulánico los días previos, decidimos asociar a clindamicina la gentamicina, en base a la proximidad de la lesión con reservorios de gérmenes gram negativos, como es la zona perianal. Al alta el tratamiento por vía oral se estableció en función del cultivo y el antibiograma obtenido a partir del tejido tras el drenaje espontáneo. En el caso clínico número 2 preferimos continuar con amoxicilina-clavulánico ya que el paciente permanecía apirético tras el desbridamiento con ese tratamiento.

El ingreso hospitalario se recomienda en caso de signos de infección sistémica o refractaria a tratamiento oral, celulitis severa o factores de riesgo como diabetes o inmunodepresión (7). Uno de nuestros pacientes presentaba fiebre, leucocitosis con desviación izquierda, mientras que el caso número 2, precisó ingreso para practicar desbridamiento y control local de la celulitis durante al menos 48 horas.

El desbridamiento de la herida debe realizarse si hay evidencia de necrosis o fluctuación por colección purulenta y/o afectación del estado general, previa limpieza de la misma con agua y jabón y posteriormente con una solución bactericida y virucida (povidona yodada al $1 \%$ ), debiendo obtener muestras para cultivo y así poder asignar un tratamiento antibiótico en base al antibiograma $(3,7)$, si no responde al tratamiento empírico.

En cuanto al cierre primario de la herida, actuamos de acuerdo con la mayoría de los autores $(3,9)$, que evitan dicho cierre cuando hay signos de infección, o han transcurrido más de 24 horas desde que se produjo la lesión. 


\section{CONCLUSIONES}

Dada la prevalencia de relaciones sexuales en las que se incluye sexo oral, la anamnesis ante las lesiones peneanas, debe incluir referencias explícitas a este tipo de prácticas.

La precocidad en el tratamiento tanto médico como quirúrgico de estas lesiones puede minimizar la magnitud de la afectación local o sistémica, siendo la amoxicilinaclavulánico una combinación adecuada como primera elección.

\section{BIBLIOGRAFÍA y LECTURAS RECOMENDADAS ( ${ }^{*}$ lectura de interés $y^{*}$ lectura fundamental)}

**1. ROSEN, T.: "Penile ulcer from traumatic orogenital contact". Dermatology Online Journal, 11: 18, 2005.

*2. GEIST, R.F.: "Sexually related trauma". Emerg. Med. Clin. N. Amer., 6: 439, 1988.

3. WOLF, S. Jr.; GOMEZ, R.; McANINCH, J.: "Human bites to the penis". J. Urol., 147: 1265, 1992.

*4. GRIEGO, R.D.; ROSEN, T.; ORENGO, I.F. y cols.: "Dog, cat and human bites: A review". J. Am. Acad. Dermatol., 33: 1019, 1995.

**5. ROSEN, T.; CONRAD, N.: "Genital ulcer caused by human bite to the penis". Sexually transmitted diseases, 26: 527, 1999.

**6. GOLDSTEIN, E.J.C.: "Management of human and animal bite wounds". J. Amer. Acad. Derm., 21: 1275, 1976.

*7. RANDY, A.; TAPLITZ.: "Managing bite wounds. $\mathrm{Cu}-$ rrently recommended antibiotics for treatment and prophylaxis". Postgrade Medicine, 2: 116, 2004.

**8. PIOT, P.; DUNCAN, M.; VAN DYCK, E. y cols.: "Ulcerative balanoposthitis associated with non-syphilitic spirochaetal infection". Genitourin Med., 62: 44, 1986.

9. HARRISON.: "Principios de medicina interna". Capítulo 127: Complicaciones infecciosas de las mordeduras (15 ${ }^{\text {a }}$ Edición), pag 968-973, 2001.

10. CALLAHAN, M.: "Controversies in antibiotics choices for bite wounds". Annals of emergency medicine, 17: 1321, 1988. 